\title{
A Percepção dos Enfermeiros sobre a Participação Familiar na Reabilitação de Idosos com Acidente Cerebrovascular
}

Livia de Sousa Rodrigues $^{1}$; Kenya Waléria de Siqueira Coelho Lisboa ${ }^{2}$; Gylmara Bezerra de Menezes Silveira ${ }^{3}$

Resumo: No Brasil os modos de assistir à saúde da população vêm sendo modificados progressivamente ao longo dos anos, resultando no atual modelo de atenção à saúde dos cuidados básicos, com atuação da atenção básica no âmbito da reabilitação implicando na relevância da Equipe de Saúde da Família junto aos núcleos familiares onde o AVC causou uma condição incapacitante de um de seus membros. O presente estudo é do tipo qualitativo exploratório e visou descrever a percepção de enfermeiros da Estratégia Saúde da Família sobre a contribuição de cuidadores/familiares para a reabilitação de idosos com Acidente Vascular Cerebral no município de Várzea Alegre - CE, com a aplicação de questionários a esses profissionais. Os sujeitos desse estudo são enfermeiros com idade superior a 26 anos e atuam na mesma equipe há mais de um ano, conhecendo relativamente bem os idosos vitimados por AVC aí residentes. Relatos demonstram que o vínculo existente entre os cuidadores e os idosos são consangüíneos, subsistindo uma relação afetiva, carinhosa, atenciosa, mas também de descuido em alguns momentos. As vantagens da permanência do cuidador acompanhando a reabilitação incluem cuidados físicos e psicossociais. As desvantagens compreendem aspectos culturais e psicossociais como o baixo nível de educação escolar e o isolamento e desgaste vivenciado ao assumir o cuidado do familiar. A atuação dos enfermeiros fica restrita aos cuidados físicos, bem como à educação em saúde para a realização dos mesmos. Existe uma preocupação com o fortalecimento do vínculo enfermeiro/ cuidador. Os familiares buscam ajuda junto à Equipe de Saúde da Família através da instrumentalização com orientações, medicações e ferramentas para a reabilitação da vítima de AVC. Somente a ampliação do foco de abordagem no atendimento domiciliar ao indivíduo afetado e à sua família possibilitará uma assistência pautada no holismo e a tão sonhada integralidade proposta pelo Sistema Único de Saúde - SUS.

Palavras-Chave: Enfermagem, cuidadores, cerebrovascular.

\section{The Perception of Nurses on the Family Participation}

\begin{abstract}
In Brazil the ways of watching people's health have been progressively modified over the years, resulting in the current model of health care basic care, working primary care within the rehabilitation implying the importance of the Health Team Family together to households where the CVA caused a disabling condition of one of its members. This study is exploratory qualitative and aimed to describe the perception of nurses of the Family Health Strategy on the contribution of caregivers / family members for the rehabilitation of elderly patients with Cerebrovascular Accident in the municipality of Várzea Alegre - CE, applying questionnaires to these professionals. The participants of this study were nurses over the age of 26 years and work on the same team for more than a year, knowing relatively well the elderly victims of CVA residing there. Reports show that the link between the caregivers and the elderly are consanguineous, subsisting an affective relationship, loving, caring, but also careless at times. The caregiver permanency advantages following the rehabilitation include physical and psychosocial care. The disadvantages include cultural and psychosocial factors such as low levels of education and isolation experienced wear and take family care. The role of nurses is restricted to the physical care and health education for their realization. There is concern about the strengthening of the nurse / caregiver relationship. Family members seek help from the Family Health Team through the instrumentation with directions, medications and tools for the rehabilitation of CVA victim. Simply expanding the approach of focusing on home care to the affected individual and his family will allow for a guided tour in holism and the long awaited full proposal by the Unified Health System - UHS.
\end{abstract}

Keywords: Nursing, caregivers, cerebrovascular.

\footnotetext{
${ }^{1}$ Possui graduação em Enfermagem pela Universidade Regional do Cariri (2006), e Especialização em Saúde da Família pela mesma Instituição de Ensino Superior (2010). Aluna do Mestrado Profissional em Saúde da Família (MPSF) da Rede Nordeste de Formação em Saúde da Família (RENASF) - nucleadora Universidade Regional do Cariri (URCA). E-mail: liviarodrigues_enf@hotmail.com;

${ }^{2}$ Enfermeira .Professora assistente do curso de graduação em Enfermagem da Universidade Regional do Cariri- URCA. Mestrado em Nutrição em Saúde Pública pela Universidade Federal de Pernambuco - UFPE(2001).E-mail:kenyacoelholisboa @ uol.com.br

${ }^{3}$ Coordenadora de Enfermagem do Centro Cirúrgico no Hospital Regional do Cariri. Especialista em Urgência e Emergência, em Bloco Cirúrgico e clínica médica. E-mail: Mara_bezerra@ hotmail.com.
} 
dos mesmos. Existe uma preocupação com o fortalecimento do vínculo enfermeiro/ cuidador. Os familiares buscam ajuda junto à Equipe de Saúde da Família através da instrumentalização com orientações, medicações e ferramentas para a reabilitação da vítima de AVC. Somente a ampliação do foco de abordagem no atendimento domiciliar ao indivíduo afetado e à sua família possibilitará uma assistência pautada no holismo e a tão sonhada integralidade proposta pelo Sistema Único de Saúde - SUS.

Palavras-Chave: Enfermagem, cuidadores, cerebrovascular.

\section{Introdução}

A população mundial vem atravessando, nos últimos anos, uma etapa de transição no que diz respeito à demografia e à epidemiologia. Este processo se manifesta em decorrência da melhoria da qualidade de vida, sendo também uma consequiência da substituição das doenças infecto-parasitárias DIPs - pelas doenças crônico-degenerativas nos perfis de morbimortalidade.

No Brasil, esta realidade é revestida de peculiaridades e especificidades, uma vez que, segundo Costa (2003) nos países em desenvolvimento esta transição acontece em meio à pobreza e à desigualdade social características à maioria da população.

Silva Junior et al (2003, p.294) defendem que "a caracterização mais apropriada dessa complexa conjuntura epidemiológica em que vivemos é de uma superposição de perfis". Esta, segundo o mesmo autor, é resultado da ocorrência simultânea de doenças não transmissíveis, das lesões por acidentes e por violências, bem como das DIPs.

Neste universo de doenças não transmissíveis Costa (2003) relata como principais causas de mortalidade em idosos brasileiros as doenças circulatórias, doenças respiratórias e neoplasias, destacando-se entre as afecções circulatórias as patologias cerebrovasculares.

No contexto ora descrito, vislumbra-se os possíveis desfechos para o acidente cerebrovascular. Nem sempre este conduz o indivíduo acometido ao óbito. Muitas vezes, a sobrevivência do mesmo gera uma condição incapacitante, o que revela outra particularidade no sentido de demandar dos serviços de saúde uma postura em relação à vítima do AVC - Acidente Vascular Cerebral, bem como às pessoas que estão à sua volta ao longo deste processo de cuidado.

Bocchi \& Ângelo (2005) ressaltam que doenças como o AVC e o IAM - Infarto Agudo do Miocárdio - podem levar o indivíduo afetado a condições de deficiência parcial ou total repercutindo não só nele próprio, mas também em sua família e na sociedade.

Desta forma, surge um novo ator social no processo: a família. Este ente acometido está inserido num grupo familiar do qual participa, em maior ou menor intensidade, a depender da realidade vivenciada pelos seus membros. No contexto ora discutido, a família como entidade indissolúvel passa a constituir alvo de assistência por parte dos serviços de saúde, sendo o seio familiar o local preferencial para a reabilitação do ser afetado pelo AVC após a fase aguda do mesmo. 
Segundo Marcon, Radovanovic, Waidman, et al (2005, p.117)

no contexto atual da assistência à saúde, as famílias têm assumido uma parcela considerável de responsabilidade na prestação do cuidado à saúde de seus membros, especialmente àqueles com problemas crônicos, arcando com a continuidade do cuidado até a completa recuperação do familiar ou, quando esta não é possível, com a condição crônica da doença e suas conseqüentes seqüelas.

Em nosso país os modos de assistir à saúde da população vêm sendo modificados progressivamente ao longo dos anos, resultando no atual modelo de atenção à saúde baseado nos cuidados básicos. Esta concepção é ratificada por Brasil (2006, p.11) ao colocar que

O Programa Saúde da Família (PSF) criado em 1994 consolidou-se como estratégia de organização da atenção básica do Sistema Único de Saúde (SUS) propondo uma mudança de modelo e contribuindo para a efetiva melhoria das condições de vida da comunidade.

O impacto observado nas condições de vida da população, e atribuído pelo autor à implantação do PSF, conduz a uma reflexão no que concerne ao potencial modificador desta estratégia sobre o perfil de morbimortalidade brasileiro, bem como sobre as condições crônicas e incapacitantes decorrentes de eventos como um acidente cerebrovascular.

Brasil (2006, p.12) expõe que

A Política Nacional de Atenção Básica, regulamentada pela Portaria GM nº 648 de 28 de março de 2006, caracteriza-se por desenvolver um conjunto de ações de saúde, no âmbito individual e coletivo, que abrangem a promoção e a proteção à saúde, a prevenção de agravos, o diagnóstico, o tratamento, a reabilitação e a manutenção da saúde.

Desta forma, observando a atuação da atenção básica no âmbito da reabilitação, em nível individual e coletivo, pressupõe-se a relevância da Equipe de Saúde da Família junto aos núcleos familiares onde o AVC tenha sido responsável pela condição incapacitante de um de seus membros.

"No Brasil, o AVC vem ocorrendo em idade precoce, com uma letalidade hospitalar, em um mês, em torno de 50\%; dos que sobrevivem, 50\% ficam com algum grau de comprometimento" (BRASIL, 2001, p.10).

Este fato possui uma forte representação para a Atenção Básica, uma vez que a taxa de sobrevida leva este indivíduo de volta para o seio de sua família, tornando a Equipe de Saúde da Família da área de abrangência correspondente a responsável pela continuidade do processo de reabilitação do mesmo.

“A equipe de Saúde da Família deve ser composta, no mínimo, por 1 médico generalista [...], 1 enfermeiro, 1 auxiliar de enfermagem e de 4 a 6 Agentes Comunitários de Saúde" (WEIRICH, TAVARES \& SILVA, 2004, p.173). 
Esta equipe é constituída pelos profissionais indicados para a prestação da assistência holística aos indivíduos, à família e à comunidade como um todo.

O município de Várzea Alegre, localizado na Região do Cariri Cearense, adota a Estratégia Saúde da Família como modelo de Atenção Básica. O referido município, cuja população residente, de acordo com dados do IBGE- 2007, é de 37.740 habitantes, possui 12 equipes de Saúde da Família em sua rede de atenção básica, que conta também com seis equipes de Saúde Bucal, um Centro de Apoio Psicossocial - CAPS - e um Núcleo de Apoio à Saúde da Família - NASF.

Em estudo realizado com cuidadores/ familiares de vítimas de AVC no âmbito hospitalar, Rodrigues, Alencar \& Rocha (2009, p.277) concluíram que

[...] as modalidades de cuidados não são totalmente conhecidas pelos cuidadores familiares. Estes consideram "cuidado" apenas aquele realizado na esfera física do indivíduo, esquecendo as ações direcionadas à reabilitação social e psicológica.

O convívio com vítimas de AVC e com seus familiares/ cuidadores na prática de atuação na Atenção Básica, tornou possível o vislumbre de outro aspecto de uma mesma situação. Se, por um lado, a assistência hospitalar deixa uma lacuna no que diz respeito ao cuidado direcionado aos familiares das pessoas acometidas por AVC, a estratégia saúde da família não deve se omitir no que concerne à assistência domiciliar, enfocando no processo de cuidado o indivíduo diretamente afetado e o núcleo familiar onde este está inserido.

Neste âmbito, a atuação do enfermeiro está na dependência do reconhecimento do papel da família enquanto agente de cuidado no domicílio, bem como dos efeitos deste cuidado no processo de reabilitação holística do idoso vitimado por um AVC.

Potter \& Perry (2002) alertam para a importância de conhecer a dinâmica dos relacionamentos familiares para que os membros da família possam ser trabalhados como facilitadores nos cuidados domiciliares.

O estabelecimento de um relacionamento enfermeiro-família-paciente que considere as particularidades de cada situação e as individualidades das pessoas envolvidas, pode influenciar positivamente no processo de reabilitação de indivíduos com AVC. Para tanto, é necessário que o enfermeiro perceba a família como sujeito de cuidado para seus membros e atue como agente no empoderamento desta unidade indissolúvel para solução dos seus problemas de saúde/doença.

A relevância de um estudo desta natureza reside no fato de que a percepção do enfermeiro acerca da relação estabelecida entre a família e o idoso doente é determinante para o direcionamento adequado de suas ações, com vistas a uma assistência pautada no fortalecimento dos laços afetivos e efetivos presentes nos contextos familiares.

O presente ensaio objetivou Descrever a percepção de enfermeiros da Estratégia Saúde da Família sobre a contribuição de cuidadores/familiares para a reabilitação de idosos com Acidente 
Vascular Cerebral. Complementarmente, Identificar junto aos enfermeiros as vantagens/ desvantagens encontradas na atuação do cuidador/familiar para a reabilitação do idoso vitimado por AVC; Descrever a relação existente entre os enfermeiros da Estratégia Saúde da Família e os cuidadores/familiares de idosos com AVC.

\section{Marco Conceitual}

\section{Envelhecimento, incapacidade e família}

O envelhecimento populacional é uma realidade que vem se concretizando em escala global. No Brasil esse processo tem ocorrido num ritmo acelerado. "No ano 2000, os idosos constituíam 9\% da população brasileira. A expectativa de vida [...] e o aumento da população idosa vêm ocorrendo de forma muito rápida no Brasil” (COSTA, 2003, p.499).

As consequiências do aumento da longevidade são as mais variadas possíveis, cursando desde modificações nos arranjos familiares até a incapacidade vivenciada por muitos idosos em decorrência das afecções crônicas que acometem em larga escala essa parcela da população.

No universo das morbidades mais comuns na faixa etária em questão destaca-se o Acidente Vascular Cerebral que, além de episódios fatais pode provocar reduções importantes e adicionais na capacidade funcional do indivíduo idoso potencializando as situações de dependência a que o mesmo encontra-se exposto.

"O acidente vascular cerebral é uma doença dos neurônios motores superiores e resulta na perda do controle voluntário em relação aos movimentos motores" (SMELTZER \& BARE, 2002, p.1580). As mesmas autoras consideram ainda, que tal condição mórbida acomete a linguagem e a comunicação, e que também provoca disfunções da percepção visual, perdas sensoriais e, dependendo da área cerebral afetada, pode comprometer a capacidade de aprendizado, memória ou outras funções intelectuais corticais superiores, refletindo-se em problemas psicológicos manifestados por labilidade emocional, hostilidade, frustração, ressentimento e falta de cooperação.

Desta forma, podemos considerar o acometimento do indivíduo idoso por tal patologia como um evento que traz consigo déficits importantes para sua funcionalidade, fazendo com que o mesmo perca, parcial ou totalmente, a autonomia e a capacidade de autocuidado. No contexto que se desenha a partir de tal acontecimento, ganha espaço a família em seu papel moral e legal de cuidadora, uma vez que,

No Brasil, a Constituição de 1988 considera responsabilidade da família, da sociedade e do Estado o suporte ao idoso, além do fornecimento de subsídios que garantam sua participação na comunidade, a defesa de sua dignidade e bem-estar e a garantia do direito à vida (MOREIRA \& CALDAS, 2007, p. 521). 
Porém, a família, na maioria das vezes, não está preparada para cuidar de seus idosos, uma vez que este cuidado perpassa aspectos físicos, sociais e psicológicos. Tendo em vista o despreparo dos grupos familiares, o enfermeiro tem delineado seu papel no momento de prestar assistência ao indivíduo e à família de modo que se configura como sendo o provedor do suporte necessário, em termos de conhecimentos e apoio emocional, para conviver com a incapacidade.

\section{O Ser Enfermeiro cuidando da família em condições incapacitantes}

O apoio de que a família necessita para enfrentar a situação de incapacidade ora vivenciada por um de seus membros deve partir da equipe de saúde, principalmente dos profissionais de enfermagem, uma vez que estes são responsáveis pelo cuidado direto ao paciente durante a hospitalização e, a partir da alta hospitalar, o cuidado deve ser continuado no âmbito das Equipes de Saúde da Família.

“A família pode ter dificuldade em aceitar a incapacitação do paciente e pode ser irreal em suas expectativas" (SMELTZER \& BARE, 2002, p.1588). Esse fato pode ser complicado pela negação que muitas famílias têm a tendência de apresentar, sendo que

\footnotetext{
Muitos parentes de pacientes de acidentes vasculares cerebrais manuseiam melhor as alterações físicas que os aspectos emocionais do cuidado. A família deve ser preparada para esperar episódios ocasionais de labilidade emocional (SMELTZER \& BARE, 2002, p.1588).
}

No contexto familiar as alterações no estilo de vida de um dos membros afetam o modo de viver de todo o grupo. As adequações tornam-se necessárias para promover o cuidado visando à reabilitação tanto individual quanto coletiva, pós- AVC.

"A finalidade de uma intervenção de enfermagem é efetuar a mudança" (WRIGHT \& LEAHEY, 2002, p.20).

As alterações no âmbito domiciliar cursam desde mudanças na estrutura física dos ambientes até a renúncia de alguns membros da família em relação a suas atividades sociais em favor da assistência a ser prestada ao seu familiar doente, pois

Quando um membro da família fica doente, todos os membros são afetados. Dependendo da natureza do problema de saúde, os membros da família podem necessitar fazer várias adaptações em seus estilos de vida existentes, ou mesmo reestruturá-los (SMELTZER \& BARE, 2002, p.89)

Um agravante é que, muitas vezes essa assistência não é prestada de maneira adequada, abordando todos os aspectos ligados ao indivíduo e ao coletivo, prolongando, desta forma, o período 
de dependência por tempo indeterminado. É provável que, se a família fosse preparada para o desempenho de seu papel de cuidadora holística, o tempo de cuidado e a sobrecarga vivenciada poderiam ser reduzidos.

"A dependência não é um estado permanente, mas um processo dinâmico cuja evolução pode se modificar e até ser prevenida ou reduzida com a existência de ambiente e assistência adequados" (TRELHA, NAKAOSKI \& FRANCO et al, 2005, p.45).

Vivenciada e encarada dessa maneira, a dependência passa a se configurar não mais como o fim da vida produtiva do indivíduo, mas sim como um momento onde a família como um todo deve contribuir para a reabilitação do ente acometido.

A preparação adequada da família para o enfrentamento do processo mórbido que acomete um de seus membros pode diminuir o impacto das incapacidades no cotidiano da mesma. O enfermeiro, como profissional do cuidado, deve estar presente no apoio ao grupo familiar acometido e conhecer a inserção de cada membro nas relações sociais que ali se estabelecem para que assim possa atuar de maneira efetiva para a reabilitação da vítima de AVC.

É por isso que conhecer e entender o cotidiano de cuidado das famílias, a percepção que elas têm de seus encontros com os profissionais de saúde, suas estratégias para manter ou recuperar o equilíbrio e, por conseguinte, a qualidade de vida, tem se mostrado importante e necessário para direcionar a assistência (MARCON, RADOVANOVIC \& WAIDMAN et al, 2005, p.119).

O suporte familiar para promover a saúde é visto como crítico no enfrentamento de crises e de doenças. A família, por sua vez, necessita de suporte externo para o exercício desta função de rede de apoio.

Além do apoio familiar, a reabilitação do paciente requer a compreensão e o apoio dos profissionais de saúde no sentido de acentuar suas potencialidades e minimizar suas limitações, ajudando-o a recuperar seus sentimentos de auto-estima positiva (FLÁVIO \& ZAGO, 1999, p.68).

Forma-se então um grande grupo composto pelo indivíduo portador de incapacidade, sua família e o enfermeiro, objetivando, principalmente, o fortalecimento para as adaptações necessárias à condição mutável proporcionada pelo processo de reabilitação, cujos resultados dependem, não apenas de condições individuais, mas também da relação de ajuda estabelecida entre todos os envolvidos no contexto criado pelo evento incapacitante.

Vale lembrar que "o enfoque dominante da avaliação de enfermagem e intervenção na família deve ser a reciprocidade entre saúde, doença e família e entre paciente, família e a enfermeira" (WRIGHT \& LEAHEY, 2002, p.13).

No entanto, o desenvolvimento dessa reciprocidade encontra-se na dependência de uma teia de relações que se estabelecem no contexto domiciliar, envolvendo o grupo familiar, o indivíduo portador das sequielas provocadas pelo AVC e os profissionais participantes do processo de reabilitação. O 
estabelecimento da relação de ajuda, que é determinante para o sucesso da evolução dos fatos e momentos, é conseguido a partir do despertar no paciente e na família da necessidade de interação recíproca com a equipe de reabilitação. Através desta reciprocidade o indivíduo, bem como sua família, sentem-se envolvidos com o profissional atuando junto a ele para a melhoria da qualidade de vida dos envolvidos.

“A pessoa que tem cuidado se sente envolvida e afetivamente ligada ao outro" (BOFF, 1999, p.92).

Seguindo tal caminho, e utilizando como recurso suas habilidades de educador em saúde, o enfermeiro poderá alcançar o objetivo da reabilitação holística do ser afetado pelo AVC, reduzindo suas incapacidades e valorizando suas capacidades, de forma que este se sinta capaz de progredir rumo à sua qualidade de vida.

\section{Percurso Metodológico}

\section{Tipo de Estudo}

O estudo ora desenvolvido é do tipo exploratório descritivo e utiliza abordagem qualitativa.

De acordo com Souza, Skubs \& Brêtas (2007, p. 264) “[...] a pesquisa qualitativa é fundamental em estudos humanísticos, pois qualifica o objeto de conhecimento: o ser humano e a sociedade".

Este estudo visa explorar o universo das percepções dos profissionais envolvidos no processo, bem como os significados atribuídos às relações entre enfermeiros e cuidadores/ familiares e entre ambos e os pacientes vitimados por um acidente cerebrovascular. Sakata et al (2007, p.660) afirmam que " a pesquisa qualitativa se preocupa, nas ciências sociais, com um nível de realidade que não pode ser quantificado".

Objetivamos, desta forma, a qualificação do objeto de estudo considerando a subjetividade e a dinamicidade que envolve o mesmo.

\section{Locus da pesquisa}

O trabalho foi desenvolvido no município de Várzea Alegre, localizado no âmbito da $20^{\mathrm{a}}$ Célula Regional de Saúde - CRES, na macrorregião do Cariri, ao sul do estado do Ceará.

O município possui 12 Equipes de Saúde da Família distribuídas nas zonas urbana e rural de seu território. As equipes possuem a composição mínima de um enfermeiro, um médico, um auxiliar 
de enfermagem, um agente administrativo e de cinco a dez agentes comunitários de saúde - ACS. A rede básica de saúde do município onde foi realizado o estudo possui ainda seis equipes de Saúde Bucal, um Centro de Apoio Psicossocial - CAPS e um Núcleo de Apoio à Saúde da Família - NASF.

\section{Indivíduos incluídos na amostra}

Os sujeitos do estudo são os enfermeiros da Estratégia Saúde da Família de Várzea Alegre CE, uma vez que estes são os responsáveis diretos pelo planejamento, supervisão e execução da assistência prestada à população adscrita.

Foram incluídos na amostra os sujeitos que se enquadraram nos seguintes critérios:

1) Possuir formação de bacharel em enfermagem;

2) Atuar na Estratégia Saúde da Família no município de Várzea Alegre - CE;

3) Aceitar participar voluntariamente do estudo.

Mesmo se enquadrando nos critérios acima citados, quatro enfermeiros não devolveram os questionários para análise da pesquisadora, constituindo-se a amostra do estudo por apenas sete dos onze potenciais sujeitos do mesmo.

\section{Coleta de dados}

O primeiro questionário foi entregue no dia 20 de maio de 2009 e o último foi devolvido à pesquisadora no dia 10 de junho do mesmo ano.

Inicialmente foi realizado um teste do instrumento de coleta de dados visando verificar a adequação deste aos sujeitos e ao objeto a ser pesquisado. Os indivíduos incluídos no pré-teste foram enfermeiros discentes do curso de especialização em Saúde da Família da Universidade Regional do Cariri - URCA.

De acordo com Marconi \& Lakatos (2001, p.130) "o pré-teste é sempre aplicado para uma amostra reduzida, cujo processo de seleção é idêntico ao previsto para a execução da pesquisa [...]”. A realização do pré-teste pressupõe a alteração do instrumento e/ou do processo de coleta de dados, caso seja identificada essa necessidade.

O instrumento utilizado foi o questionário. Esta maneira de coletar os dados foi escolhida levando-se em consideração que o grande número de atividades no dia-a-dia dos profissionais alvo deste estudo requer uma maior flexibilidade e liberdade de escolha quanto ao horário e local para fornecimento dos dados necessários ao alcance dos objetivos propostos. 


\section{Organização e análise dos dados}

Uma vez coletados, os dados foram organizados de acordo com categorias pré-estabelecidas no questionário. Minayo (2001, p.70) ressalta que trabalhar com categorias consiste em "agrupar elementos, idéias ou expressões em torno de um conceito capaz de abranger tudo".

A análise das categorias baseou-se na literatura disponível sobre o assunto e em conhecimentos decorrentes da prática diária da pesquisadora.

\section{Aspectos Éticos}

O gestor local do SUS no município de Várzea Alegre - CE - Secretário Municipal de Saúde nos concedeu sua autorização para realização do trabalho através de um documento específico para tal finalidade, assinado em 18 de maio de 2009.

O projeto foi enviado para avaliação pelo Comitê de Ética em Pesquisa - CEP - da Faculdade de Medicina de Juazeiro do Norte - FMJ.

Os sujeitos da pesquisa foram selecionados mediante leitura e assinatura do Termo e consentimento Livre e Esclarecido. Nos resultados da pesquisa os mesmos receberam a designação de “Enf” seguido por um numeral cardinal (por exemplo, "Enf. 1").

Os princípios éticos da Resolução 196/96 (BRASIL, 1996) foram obedecidos, respeitando todas as recomendações para pesquisas envolvendo seres humanos. Levamos em consideração a individualidade dos envolvidos, a liberdade de desligar-se da pesquisa em qualquer momento de sua execução, bem como a manutenção da identidade dos mesmos em sigilo e a utilização legal do termo de consentimento livre e esclarecido.

\section{Discussão dos Resultados}

\section{Qualificando a amostra}

Ao iniciar este trabalho selecionamos a amostra dentre os enfermeiros da estratégia Saúde da Família do município que se configura como cenário para nossa pesquisa.

Os sujeitos desse estudo são enfermeiros na faixa etária superior a 26 anos e estão, em sua totalidade, atuando na mesma área de abrangência há mais de um ano. 
Os indivíduos pesquisados demonstraram conhecer relativamente bem os idosos vitimados por AVC em sua área de abrangência, o que mostra a importância da longitudinalidade da Atenção Primária em Saúde, onde a equipe acompanha as pessoas residentes em sua área de abrangência fazendo seu seguimento ao longo do tempo numa linha transversal.

\section{Enfermeiros e a realidade pesquisada}

De acordo com as respostas obtidas, os idosos sequelados de AVC, após o evento, voltam a residir com seus familiares, fato este que confirma a família como agente de cuidado e apoio para seus membros em situações de saúde, doença ou na presença de algum evento incapacitante.

Rice (2001) apud Lacerda e Oliniski (2004, p. 239) conceitua família como “[...] um grupo de pessoas que vivem juntas ou em contato íntimo, cuidam umas das outras e proporcionam cuidado, apoio, criação e orientação para seus membros dependentes, uns aos outros".

Levando em consideração este conceito, podemos dizer que a relação familiar pressupõe além da consangüinidade, um vínculo afetivo, de cuidado e interdependência.

Os relatos demonstram que o vínculo existente entre os cuidadores/ familiares e os idosos com AVC é de consangüinidade, na maioria das vezes, subsistindo uma relação afetiva, de carinho, atenção, mas também de descuido em alguns momentos.

existe um vínculo familiar, às vezes de carinho, atenção, responsabilidade e às vezes, descuido (Enf 5)

Nesse sentido, foram consideradas por um enfermeiro as alterações nas relações familiares advindas do evento incapacitante.

considero que o AVC altera as relações familiares, na maioria dos casos, os idosos dependentes e seus cuidadores desinformados vivenciam sentimentos de ansiedade, frágeis não conseguem manter continuamente, vínculos afetivos.Alguns cuidadores vêem a situação como um fardo, sentem-se despreparados para realizar as fatigantes tarefas necessárias aos cuidados com o idoso sequelado de AVC (Enf 6).

Este fato é confirmado por Lacerda \& Oliniski (2004, p.242) ao afirmar que "[...] a necessidade constante e contínua de cuidados leva o cuidador familiar ao cansaço e esgotamento, uma vez que possui outras atribuições e precisa somar a elas os cuidados, que não são poucos, de seu familiar".

Assim, fica implícita a necessidade de ajuda inerente aos cuidadores familiares que, além do estresse provocado pela condição vivenciada pelo seu familiar, enfrentam o cansaço físico decorrente 
da execução dos cuidados relacionados à reabilitação e ao atendimento às necessidades básicas do ente portador de incapacidade.

Sobreveio, ainda, a realidade presente nos casos em que o familiar acometido é o provedor financeiro da família, inclusive do seu cuidador, bem como as situações de cuidadores informais que são remunerados para tal fim.

o vínculo é de consangüinidade (familiares), afetividade, dependência (aposentadoria) ou sem nenhum vínculo como no caso das pessoas contratadas só para este fim (Enf 7).

O contexto ora pesquisado nos permite verificar uma realidade composta por um emaranhado de relações que se estabelecem no momento de cuidar de um familiar que vivencia uma situação de incapacidade. Relações entre a família, cenário, sujeito e objeto de cuidado.

De acordo com Perlini \& Faro (2005, p.155) “A experiência de cuidar de alguém acometido por AVC em casa tem se tornado cada vez mais freqüente no cotidiano das famílias".

Este viés nos leva a confirmar a percepção da importância do cuidado familiar, uma vez que estes cuidadores necessitam de preparo adequado para assistir o familiar acometido. No caso específico das famílias cujo membro foi atingido por um evento cerebrovascular, Chagas \& Monteiro (2004, p.194) afirmam que "o núcleo familiar, entretanto, encontra-se desestruturado devido ao impacto da doença e, com isso, a família pode apresentar dificuldades em assistir o paciente por conta das restrições impostas a ele pelo AVC".

Segundo as mesmas autoras, é nesse contexto que o enfermeiro encontra espaço propício para o desenvolvimento de suas atribuições de educador em saúde, buscando tranqüilizar as famílias e instrumentalizá-las para o cuidado ao seu familiar acometido.

A assistência que deve ser prestada pela Equipe de Saúde da Família ultrapassa os limites dos cuidados físicos visando o restabelecimento orgânico. Mais que isso, a equipe estabelece relações e forma vínculos com as famílias, presenciando muitas vezes as angústias e os medos que os indivíduos enfrentam mediante um evento incapacitante ocorrido com um membro da família.

$\mathrm{Na}$ percepção dos enfermeiros entrevistados existem vantagens e desvantagens na permanência deste cuidador/ familiar como apoio principal na reabilitação da vítima de AVC.

[...] alguns enfermeiros vêem como positiva a interferência da família sob dois aspectos: quando ajuda a enfermagem a cuidar do paciente ou quando dá informações sobre o estado dele aos profissionais de saúde (SILVA \& BOCCHI, 2005, p. 181).

No universo pesquisado, os cuidados físicos integraram o elenco das vantagens da permanência do cuidador familiar no processo de reabilitação. 
- companhia, cuidados na alimentação, na medicação, na higiene, no controle da P. A. (Enf 1)

vantagens - medicação no horário, assim como alimentação e retornos das consultas e na reabilitação (Enf 3$)$

Cuidados psicossociais foram incluídos como coadjuvantes nesta relação de cuidado.

é que o cuidador/ familiar está quase sempre ao lado do sequelado e conhece os seus hábitos (Enf 2)

vantagens - vínculo afetivo, compromisso (Enf4)

vantagens - com amor e carinho a doença torna-se mais amena (Enf5)

Vantagens: - vínculo afetivo; - conhecimento dos hábitos do idoso, anteriores ao AVC; - solidariedade (Enf6)

as vantagens são que estes cuidadores são pessoas com quem o idoso tem muito contato, existindo deste modo o carinho, respeito e a vontade de poder ajudar na reabilitação do mesmo (Enf7)

Vale lembrar que, para a eficácia do cuidado, torna-se necessário o estabelecimento de uma relação de ajuda entre o enfermeiro e o cuidador/familiar, considerando neste contexto que, de acordo com Silva \& Bocchi (2005, p. 186), "uma relação de ajuda é benéfica quando cada participante está contribuindo, positivamente, para atender às necessidades de saúde do paciente". Esta afirmação fundamenta nosso conhecimento empírico de que a interação é algo valioso no processo de cuidar de vítimas de AVC.

Os principais pontos abordados como desvantagens da presença do cuidador/ familiar compreendem aspectos culturais e psicossociais tais como o baixo nível de educação escolar dos cuidadores e o isolamento e desgaste que este vivencia ao assumir o cuidado do familiar afetado pelo AVC.

Desvantagens - a dependência que causa para ambos (Enf1)

Desvantagem - é que geralmente o cuidador/ familiar não tem conhecimentos científicos e práticos para tal função (Enf2)

Desvantagens - parentes fica com o benefício e não faz uso adequado (Enf3)

Desvantagens - muitas vezes não querem fazer o que foi orientado pelo familiar (Enf4)

Desvantagens - cansaço físico (Enf5) 
Desvantagens: - falta de conhecimento dos cuidados ao idoso sequelado de AVC; - rotina; - Cansaço. (Enf6)

A desvantagem é porque a maioria destes cuidadores são pessoas de baixa escolaridade, o que pode prejudicar na aquisição de conhecimentos e habilidades no cuidado destes pacientes. (Enf7)

Também foi citada a questão da utilização inadequada do benefício previdenciário que, na maioria das vezes, o idoso possui. Este fato merece nossa atenção, uma vez que, segundo Souza, Skubs \& Brêtas (2007, p.267) "[...] os idosos não são apenas cuidados e ajudados por seus familiares mas também cuidam e ajudam, fato este mais visível nas famílias mais pobres".

Apesar das vantagens e desvantagens da presença do cuidador familiar relatadas neste estudo devemos considerar que

a família do idoso, principalmente daquele fragilizado e dependente, na maioria das vezes procura arranjos entre seus membros e possíveis adequações do contexto, visando o atendimento das suas necessidades (DIOGO, 2000, p.76).

Portanto, nós enquanto profissionais da saúde, devemos respeitar e compreender o esforço que os familiares demonstram para direcionar aos seus parentes o cuidado adequado de acordo com suas próprias possibilidades e reconhecer as limitações que essas famílias precisam superar para prestar tais cuidados.

\section{Enfermeiros X Cuidadores/familiares}

A realidade por nós vivenciada ainda abriga uma tendência que considera e prioriza os cuidados físicos em situações de incapacidade e dependência.

A atuação dos enfermeiros incluídos na amostra deste ensaio fica restrita ao campo dos cuidados físicos, incluindo monitorização da pressão arterial, bem como a educação em saúde para os cuidadores no que diz respeito à realização destes cuidados.

um acompanhamento na pressão arterial do paciente, na alimentação, nos cuidados com o paciente como a prevenção de escaras (nos acamados), na medicação (Enf1)

o enfermeiro deve está junto na capacitação dos familiares/ cuidadores, bem como, transmitindo conhecimentos aos cuidadores para alcance dos objetivos propostos que é o da reabilitação $($ Enf2)

em relação aos cuidados, na prevenção de escaras de decúbito - orientações sobre mudanças de decúbito, higiene, banho de sol, etc... (Enf5)

Mesmo enfatizando os cuidados físicos, pode-se observar nas respostas uma preocupação com o fortalecimento do vínculo enfermeiro/ cuidador - através das visitas domiciliares, bem como com a educação em saúde como fonte de informação e instrumento de reabilitação.

115 Id en line Revista de Psicologia. Ano 9, No. 25, Fevereiro/2015 - ISSN 1981-1179. Edição eletrônica em http://idonline.emnuvens.com.br/id 
visita domiciliar - encaminhamentos para fisioterapia, orientações quanto: medicação, alimentação e exames laboratoriais, exercícios passivos (Enf3)

o primeiro contato é logo depois do episódio, durante a visita domiciliar da equipe, onde investigamos toda a história da doença atual e repassamos o cuidado que deve receber o doente. Posteriormente, dependendo da evolução da reabilitação, fazemos outras visitas. (Enf7)

A aproximação do enfermeiro com os cuidadores/familiares deve acontecer com compreensão e paciência por parte do enfermeiro, uma vez que, de acordo com Lacerda \& Oliniski (2004, p.242) "a família encontra-se fragilizada com toda a situação vivida, colocando uma barreira natural como forma de proteção $[\ldots] "$.

Um ponto importante a ser destacado é que o cuidado, quando sistematizado, torna-se mais completo e próximo do holismo proposto tanto para o cuidador quanto para o indivíduo portador de incapacidades em consequência do AVC. A descrição dos cuidados feita pelo Enfermeiro 6 vem demonstrar a aplicabilidade desse método de cuidados na prática diária.

\footnotetext{
Aspectos organizacionais:

- conhecer os idosos sequelados de AVC, assim como seus familiares/ cuidadores a partir das informações dos agentes comunitários de saúde;

- agendar visitas domiciliares e realizá-las;

Aspectos psico-comportamentais:

- estabelecer vínculos com cuidadores/familiares;

- analisar o contexto familiar;

- perceber as deficiências e potencialidades dos cuidadores/familiares;

Aspectos de seguimento (acompanhamento):

- oferecer informações objetivas e simples, orientando os familiares quanto aos cuidados com o idoso: importância do acompanhamento por parte do Programa de Saúde da Família (PSF), uso de medicamentos, mobilidade, higiene, comunicação, dentre outros.

- informar aos cuidadores que as dificuldades virão a cada dia, mas com paciência serão superadas;

- estimular os cuidadores a buscar medidas de postura, descanso e lazer. (Enf6)
}

O fazer de enfermagem como ciência mostra, mais uma vez, sua relevância no que diz respeito ao alcance de uma assistência de qualidade pautada no planejamento e execução das ações de acordo com as necessidades humanas básicas da clientela alvo, seja ela um indivíduo, uma família ou um grupo social.

Na realidade pesquisada, a relação dos enfermeiros com os cuidadores/ familiares de idosos vitimados por AVC é bastante heterogênea, variando desde o contato esporádico em visitas domiciliares ou atividades educativas até o estabelecimento de uma relação de ajuda, buscando a satisfação das carências do cuidador no que diz respeito aos cuidados direcionados ao familiar com incapacidade e sua importância no processo de reabilitação.

Os relatos dos enfermeiros ratificam tal afirmação. 
através de visitas domiciliares, de visitas dos cuidadores/ familiares ao posto de saúde, em palestras educativas (Enf1)

relação principalmente de profissional de saúde para cuidadores procurando ser empático nas decisões (Enf2)

cada cuidador/familiar tem uma postura diferente, por isso busco conhecer $e$ estabelecer uma relação de confiança e responsabilidade, enfatizando sobretudo a importância do cuidador na reabilitação do idoso. (Enf6)

Nesta concepção, Chagas \& Monteiro (2004, p. 194) consideram que

[...] a família também precisa ser alvo dos cuidados, uma vez que o envolvimento dos familiares no processo de recuperação pode interferir positivamente na saúde do paciente.

De acordo com os depoimentos dos sujeitos da pesquisa, os familiares/ cuidadores buscam estabelecer junto à Equipe de Saúde da Família uma relação de ajuda através da instrumentalização com orientações, medicações e ferramentas para a reabilitação da vítima de AVC, como mostram as falas a seguir.

\begin{abstract}
mostram-se cuidadosos em relação ao problema, vêem sempre pegar o medicamento, solicitam verificação da $P$. A, se preocupam com a alimentação do doente, não todos, mas a grande maioria (Enf1)
\end{abstract}

tem demonstrado interesse na reabilitação, pedem visita domiciliar e orientações (Enf3)

pela situação de estresse vivenciada pelos cuidadores, a maioria chega ao PSF com certa ansiedade e medo, o que os torna vulneráveis, pouco atentos e distantes dos profissionais de saúde. Posteriormente as relações de confiança e apoio se fortalecem. (Enf6)

Cabe ao enfermeiro, nessas situações, mostrar uma postura de acolhimento em relação à vítima de AVC e à sua família como alvo de cuidados, uma vez que a mesma necessita de auxílio no que diz respeito à nova situação vivenciada. A educação em saúde também deve ser valorizada ao longo de todo o processo de cuidado, tendo em vista que o apoio buscado junto ao enfermeiro abre espaço para sua atuação na assistência e no ensino da mesma incluindo os cuidados físicos e psicossociais ao doente e à família como um todo.

De acordo com Lacerda e Oliniski (2004, p.240)

[...] a principal atividade desses profissionais é colaborar com o cliente e sua respectiva família, para que possam alcançar independência e poder administrar os cuidados necessários à situação vivida.

Neste enfoque, os enfermeiros entrevistados relataram desenvolver atividades de educação em saúde junto aos familiares de idosos vitimados por um evento cerebrovascular abordando aspectos 
individuais e coletivos, considerando toda a subjetividade do processo de ensino/aprendizagem no contexto estudado.

Os depoimentos revelam, ainda, aspectos importantes abordados na educação em saúde a essas famílias.

como as seqüelas do AVC e as dificuldades dos cuidadores são diferentes, a educação em saúde no domicílio, deve ser planejada individualmente, destaco os seguintes aspectos:

-psicológicos;

-preventivos evitando complicações urinárias, circulatórias e respiratórias; -cuidados com: higiene, alimentação e mudanças de decúbito;

-acompanhamento, reabilitação e estimulação (valorizar cada conquista do idoso sequelado de $A V C)$. (Enf6)

cuidados com a alimentação, com a tomada dos medicamentos de rotina e a verificação da pressão arterial, cuidados com a alimentação, prevenção de escaras, cuidado com quedas, um bom tratamento para com o doente, companheirismo. (Enf1)

higiene do paciente; mudança de decúbito, o carinho que devem ter em relação a estas pessoas. (Enf5)

Pode-se perceber, desta forma, a importância que os enfermeiros atribuem a um relacionamento familiar/ paciente pautado no carinho, no respeito e na atenção. Este tipo de cuidado demonstra o conhecimento que os sujeitos do estudo detém no que diz respeito ao processo de reabilitação, destacando a importância da família para a recuperação física e psicossocial do indivíduo afetado por um evento cerebrovascular.

A assistência prestada ao idoso vitimado por AVC ainda está muito pautada nos cuidados físicos e na orientação desses cuidados aos familiares/ cuidadores. Apesar desta constatação já é possível perceber um discreto direcionamento dos profissionais aos cuidados psicossociais, o que é muito evidente na preocupação destes com o vínculo existente entre os cuidadores e seus familiares acometidos.

A Estratégia Saúde da Família é um instrumento valioso na criação desse novo paradigma de cuidados, uma vez que suas equipes são responsáveis pelo acompanhamento da reabilitação desses idosos.

No entanto, é urgente que esse processo de redirecionamento da assistência seja consolidado por uma mudança de postura dos profissionais e uma influência positiva no modo de agir dos cuidadores familiares rumo ao alcance do holismo na assistência aos idosos que vivem e envelhecem com limitações decorrentes das afecções cerebrovasculares.

\section{Considerações Finais}


Um estudo desta natureza nos levou a uma reflexão sobre a prática das Equipes das Equipes de Saúde da Família direcionada às famílias em que algum membro foi vítima de um evento incapacitante. Refletimos, ainda, sobre a nossa própria relação com a população que vivencia uma situação de incapacidade no seio familiar.

De acordo com os dados obtidos na presente pesquisa foi possível perceber uma preocupação significativa dos enfermeiros pesquisados no que tange à necessidade de reabilitação da população idosa vítima de Acidente Vascular Cerebral. Vale lembrar que, na Estratégia Saúde da Família, é o enfermeiro o profissional responsável pela coordenação do cuidado na área adscrita. Desta forma o entendimento do mesmo acerca da reabilitação dos idosos com AVC e da participação da família neste processo é bastante relevante e de certo modo determinante para que a Equipe de Saúde obtenha êxito em suas atividades no campo da reabilitação.

$\mathrm{O}$ fato demonstrado pela pesquisa de que os idosos vitimados por AVC residem com seus familiares revela um aspecto importante do contexto estudado. A Equipe de saúde encontra uma rede de apoio com a qual pode contar para implementar os cuidados necessários ao idoso portador de incapacidade. Porém, os enfermeiros alvo do estudo consideram que, o fato do idoso residir com familiares não representa apenas vantagens.

As desvantagens também estão presentes neste ensejo. Entre os benefícios de tal proximidade estão a companhia, o vínculo formado, o cuidado físico e o afeto. No entanto, as desvantagens incluem o despreparo dos familiares para a prestação do cuidado e o impacto provocado em toda a família no sentido da dependência e do isolamento social a que todo o grupo fica exposto. Os cuidadores ficam sobrecarregados e a rotina torna-se cansativa e estressante.

Além disso, os profissionais da atenção básica ainda não estão suficientemente preparados para atuar na esfera psicossocial do indivíduo, das famílias e das comunidades por eles assistidas. Este fato ficou evidente quando os enfermeiros foram indagados a respeito de sua atuação junto aos cuidadores de idosos com AVC. As respostas demonstraram que esta assistência ainda é voltada predominantemente aos cuidados físicos e às orientações neste sentido. Apenas um dos enfermeiros mencionou sua atuação direcionada aos aspectos psicossociais da reabilitação.

No que tange à relação estabelecida pelos enfermeiros com os familiares/ cuidadores foi possível perceber que as tentativas estão, em sua maioria, na direção correta, sendo condizentes com o que é proposto pela literatura acerca do tema.

A educação do familiar figura como um ponto importante na assistência. No entanto, sobressaem, mais uma vez, os aspectos físicos do cuidado. A postura profissional reflete no comportamento do cuidadores em relação à Equipe de Saúde. De acordo com os sujeitos desta pesquisa os familiares, geralmente, mostram-se preocupados com os cuidados físicos que devem 
prestar a seus parentes portadores de incapacidade buscando, para tanto, insumos e orientações na unidade de saúde, aceitando passivamente aquilo que lhes é orientado.

O estado de vulnerabilidade em que estes cuidadores se encontram contribui para a aceitação das propostas que a equipe de saúde lhes trouxer e para a solicitação da presença da equipe no domicílio auxiliando neste processo. Cabe, portanto, aos gerentes do cuidado o direcionamento de atitudes no sentido de instrumentalizar essas famílias para que os idosos com AVC possam ter acesso à reabilitação biopsicossocial como é direito de todo ser humano.

Como nuance de grande importância no relacionamento enfermeiro x familiar, a educação em saúde recebeu o merecido destaque nesta rede interativa. Os relatos demonstraram que as atitudes no sentido de educar os cuidadores a trabalhar a esfera psicossocial do indivíduo e da família afetada já surgem num esboço de postura profissional que valoriza a formação e a manutenção do vínculo entre o idoso vitimado por um evento cerebrovascular e seu cuidador/ familiar.

Conforme os resultados deste estudo foi possível verificar uma realidade na qual as alternativas hoje implementadas são, de certa forma exitosas. Porém, as lacunas continuam a existir, sendo, para tanto, necessário que toda a sociedade tenha sua postura modificada no sentido de promover a reabilitação biopsicossocial do idoso com AVC.

Desta forma, a partir da experiência adquirida e do conhecimento construído com a realização desta pesquisa, propomos aos profissionais da Atenção Básica um aperfeiçoamento em sua postura profissional no sentido de atentar para questões ligadas à reabilitação física, metal e social do indivíduo vitimado por um acidente cerebrovascular.

Ressaltamos que, somente a ampliação do foco de abordagem no atendimento domiciliar a esse indivíduo e ao seu grupo familiar tornará possível a prestação de uma assistência pautada no holismo e a tão sonhada integralidade proposta pelo Sistema Único de Saúde - SUS.

\section{Referências}

BOCCHI, Sílvia Cristina Mangini \& ANGELO, Margareth. Interação cuidador familiar-pessoa com AVC: autonomia compartilhada. Ciênc. saúde coletiva. [online]. jul./set. 2005, v.10, n.3, p.729-738. ISSN 1413-8123 Disponível em: 〈http://www.scielo.br〉 .Acesso em 06 de Novembro de 2005.

BOFF, Leonardo. Saber cuidar: Ética do humano - compaixão pela terra. 4. ed. Petrópolis: Vozes, 1999.

BRASIL. Conselho Nacional de Saúde. Resolução 196/96. Decreto n. 93.933 de janeiro de 1987. Estabelece critérios sobre pesquisa envolvendo seres humanos. Bioética. V.4, n.2. Suplemento, 1996, p. 15-25.

BRASIL. Ministério da Saúde.Departamento de Atenção Básica. Envelhecimento e saúde da pessoa idosa. Brasília: 2006, 192p. 
BRASIL. Ministério da Saúde. Departamento de Atenção Básica. Guia prático do programa da Saúde da Família. Brasília: 2001.

BRASIL. Ministério da Saúde. Departamento de Atenção Básica. Manual de estrutura física das unidades básicas de saúde: saúde da família. Brasília, 2006, 72p.

BRASIL. Ministério da Saúde. Plano de Reorganização da Atenção à Hipertensão Arterial e ao Diabetes Mellitus: Hipertensão Arterial e Diabetes Mellitus. Brasília, 2001, 102p.

COSTA, Maria Fernanda Lima. Epidemiologia do Envelhecimento no Brasil. In: ROUQUAYROL, Maria Zélia \& FILHO, Naomar de Almeida. Epidemiologia em Saúde. 6.ed. Rio de Janeiro: MEDSI, 2003. Cap.16, p.499-513.

FLAVIO, Patrícia Gonçalves Custódio and ZAGO, Márcia Maria Fontão. Reabilitação vocal do laringectomizado: características culturais do processo. Rev. Latino-Am. Enfermagem . [online]. Apr. 1999, v.7, n.2, p.63-70. ISSN 0104-1169. Disponível em: 〈http://www.scielo.br> Acesso em: 16 de Outubro de 2005.

IBGE - Instituto Brasileiro de Geografia e Estatística. Contagem da População 2007: Várzea Alegre

- CE . Disponível em: <http://www.ibge.gov.br> Acesso em: 02 de dezembro de 2008.

MARCON, Sônia Silva , RADOVANOVIC, Cremilde Aparecida Trindade, WAIDMAN, Maria Angélica Pagliarini, et al. Vivências e reflexões de um grupo de estudos junto às famílias que enfrentam a situação crônica de saúde. Texto Contexto Enferm. [online]. 2005. v.14. p.116-124. Disponível em: $<$ http://scholar.google.com.br $>$ Acesso em 21 de outubro de 2008.

MARCONI, Marina de Andrade; LAKATOS, Eva Maria. Metodologia do Trabalho Científico. 6.ed. São Paulo: Atlas, 2001.

MINAYO, Maria Cecília de Souza. Pesquisa Social: teoria, método e criatividade. 18 ed. Petrópolis: Vozes, 2001.

MOREIRA, Márcia Duarte. CALDAS, Célia Pereira. A importância do cuidador no contexto da saúde do idoso. Esc Anna Nery. [online]. set.2007, v.11, n.3, p.520-525. Disponível em: < http://www.portalbvsenf.eerp.usp.br> Acesso em: 21 de outubro de 2008.

POTTER, Patrícia A. PERRY, Anne G. Grande Tratado de Enfermagem Prática: Conceitos Básicos, Teoria e Prática Hospitalar. 3. ed. São Paulo: Santos Livraria Editora, 2002.

RODRIGUES, Lívia de Sousa, ALENCAR, Ana Maria Parente G, ROCHA, Edilma Gomes. Paciente com Acidente Vascular Encefálico e a rede de apoio familiar. Revista Brasileira de Enfermagem. mai/abr.2009, v.62, n.2, p.272-277, ISSN 0034-7167.

SAKATA, Karen Namie, ALMEIDA, Maria Cecília Puntel de, ALVARENGA, Ariane de Melo, CRACO, Priscila Frederico, PEREIRA, Maria José Bistafa. Concepções da equipe de saúde da família sobre as visitas domiciliares. Revista Brasileira de Enfermagem. nov/dez. 2007. v.60. n.6, p. 659-664, ISSN 0034-7167. 
SILVA JUNIOR, Jarbas Barbosa, GOMES, Fábio de Barros Correia, CEZÁRIO, Antônio Carlos \& MOURA, Lenildo. Doenças e Agravos Não-Transmissíveis: Bases Epidemiológicas. In: ROUQUAYROL, Maria Zélia \& FILHO, Naomar de Almeida. Epidemiologia em Saúde. 6.ed. Rio de Janeiro: MEDSI, 2003. Cap. 10. p. 289-311.

SMELTZER, Suzane C, BARE, Brenda G. e cols. Considerações Individuais e Familiares Relacionadas a Doença.. In: Brunner \& Suddarth/ Tratado de Enfermagem médicocirúrgica. 9.ed. Rio de Janeiro: Guanabara Koogan,2002. v.1, cap.7, p. 86-97.

SMELTZER, Suzane C, BARE, Brenda G. e cols. Tratamento de Pacientes com Distúrbios Neurológicos. In: Brunner \& Suddarth/ Tratado de Enfermagem médico-cirúrgica. 9.ed. Rio de Janeiro: Guanabara Koogan,2002. v.4, cap.57, p. 1562-1601.

SOUZA, Rosângela Ferreira de, SKUBS, Thais, BRÊTAS, Ana Cristina Passarella. Envelhecimento e família: uma nova perspectiva para o cuidado de enfermagem. Revista Brasileira de Enfermagem. mai./jun. 2007. v.60, n.3, p. 263-267, ISSN 0034-7167.

TRELHA, Celita Salmaso. NAKAOSKI, Tatiana. FRANCO, Simone Silveira et al.Capacidade funcional de idosos restritos ao domić́lio, do conjunto Ruy Virmond Carnascialli, Londrina/PR. Semina: Ciências Biológicas e da Saúde. [online] jan./jun.2005, v. 26, n. 1, p. 37-46. Disponível em: <http://www.scielo.br> Acesso em: 21 de outubro de 2008.

WEIRICH, Claci Fátima, TAVARES, João Batista, SILVA, Klever Souza. O Cuidado de Enfermagem à Família: Um Estudo Bibliográfico. Revista Eletrônica de Enfermagem, v. 6, n. 2, p. 172-180, 2004. Disponível em: <http://www.fen.ufg.br $>$. Acesso em: 25 de setembro de 2005.

WRIGHT, Lorraine M. LEAHEY, Maurren. Enfermeiras e família: um guia para avaliação e intervenção na família. 3. ed. São Paulo: Roca, 2002.

Como citar este artigo (Formato ABNT):

RODRIGUES, L.S.; LISBOA, K.W.S.C.; SILVEIRA, G.B.M. A percepção dos Enfermeiros sobre a participação familiar na reabilitação de idosos com Acidente Cerebrovascular. Id on Line Revista de Psicologia, Fevereiro de 2015, vol.9, n.25, p. 102-122. ISSN 1981-1189. 